Published in final edited form as:

ACS Catal. 2016 July 1; 6(7): 4616-4620. doi:10.1021/acscatal.6b01384.

\title{
Anion-Abstraction Catalysis: The Cooperative Mechanism of a- Chloroether Activation by Dual Hydrogen-Bond Donors
}

\author{
David D. Ford, Dan Lehnherr, C. Rose Kennedy, Eric N. Jacobsen ${ }^{\star}$ \\ Department of Chemistry and Chemical Biology, Harvard University, Cambridge, Massachusetts \\ 02138, United States
}

\begin{abstract}
We provide here a detailed mechanistic characterization of the electrophile-activation step in a representative thiourea-catalyzed enantioselective reaction proposed to involve generation of ionpair intermediates. Comparison of catalyst-promoted substrate epimerization with catalytic alkylation points to the participation of a common intermediate in both pathways and provides conclusive evidence for anion abstraction via an SN1-like pathway involving the cooperative action of two catalyst molecules.
\end{abstract}

\section{GRAPHICAL ABSTRACT}

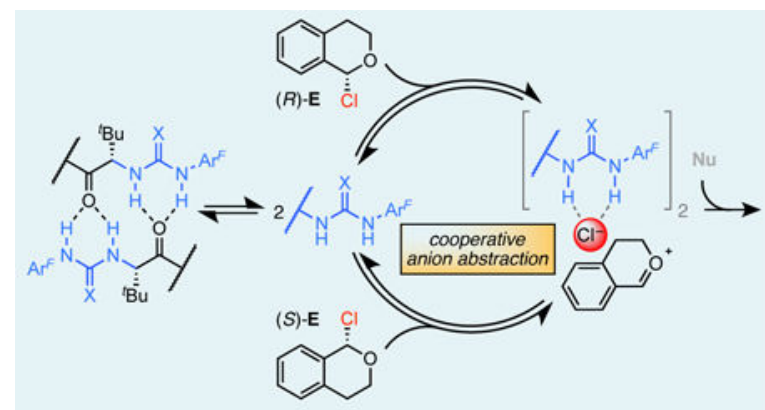

\section{Keywords}

reaction mechanism; organocatalysis; anion-binding catalysis; anion-abstraction catalysis; ionpairing catalysis

\begin{abstract}
Dual hydrogen bond (H-bond) donors such as chiral urea, thiourea, and squaramide derivatives have gained prominence as important catalysts for a variety of highly enantioselective transformations involving ion-pair intermediates. ${ }^{1,2}$ As a general principle,
\end{abstract}

\footnotetext{
*Corresponding Author Jacobsen@ chemistry.harvard.edu. ASSOCIATED CONTENT

The authors declare no competing financial interests.
} 
the H-bond donor forms a stereodifferentiated environment around a reactive cationic intermediate by binding its counteranion, thereby controlling stereoselectivity of subsequent nucleophile addition. ${ }^{1}$ Several distinct strategies for accessing the intermediate ion-pair complex have been proposed. These include: association of the H-bond donor to a preformed ion pair (Scheme 1A), ${ }^{2 \mathrm{f}} \mathrm{Br} \varnothing n$ sted acid co-catalysis, wherein the H-bond donor enhances the acidity of a weak acid by stabilizing its conjugate base (Scheme 1B), ${ }^{2 \mathrm{~d}}$ and anion abstraction from a neutral substrate (Scheme 1C). ${ }^{2 \mathrm{c}}$ This last manifold has been invoked to explain a broad range of enantioselective reactions, but the detailed mechanism of neutral electrophile activation by H-bond donor catalysts remains poorly understood.

With the aim of gleaning insight that might ultimately guide the design of improved anionabstraction catalysts, we recently undertook a detailed kinetic analysis of the enantioconvergent amido-thiourea-catalyzed alkylation of racemic a-chloroisochroman (2) with silyl ketene acetal nucleophiles (such as $\mathbf{3}$, Scheme 2 ). ${ }^{3}$ This study revealed an unusual cooperative mechanism wherein the catalyst rests as a nonproductive dimeric aggregate (1a•1a) under typical reaction conditions ( $0.1 \mathrm{M}$ in substrate, $10 \mathrm{~mol} \%$ of catalyst); deaggregation is necessary before two molecules of the catalyst recombine with the substrates to enable rate-determining $\mathrm{C}-\mathrm{C}$ bond-formation. While this analysis illuminated some of the causes for low catalyst efficiency, the specific roles of the two catalyst units in electrophile activation could not be determined through this kinetic investigation alone. Herein we describe advanced mechanistic characterization of the thioureacatalyzed substitution reaction and report decisive evidence for anion abstraction via an $\mathrm{S}_{\mathrm{N}}$ 1-like pathway.

The alkylation reaction in Scheme 2 engages racemic chloroether $( \pm)-2$ to produce a highly enantioenriched substitution product in high yield. ${ }^{2 c}$ We initiated the mechanistic investigation by probing the basis for this stereoconvergence. Two limiting mechanisms could account for the catalytic conversion of both enantiomers of $\mathbf{2}$ to the same enantiomer of alkylation product 4. In an $\mathrm{S}_{\mathrm{N}} 2$ reaction manifold, the thiourea catalysts could effect direct activation of the chloride leaving group to enable stereospecific, invertive displacement (Scheme 3A). ${ }^{4}$ Within this mechanism, racemization of 2 by either a catalystindependent (Scheme 3A-i) or a catalyst-promoted (Scheme 3A-ii) pathway must be rapid relative to alkylation in order to achieve $>50 \%$ conversion through a dynamic kinetic resolution. ${ }^{5,6}$ In contrast, in an $\mathrm{S}_{\mathrm{N}} 1$ reaction manifold, reversible catalyst-mediated ionization of the a-chloroisochroman $\mathbf{2}$ to form an oxocarbenium •chloride ion pair would activate the substrate to subsequent stereoselective nucleophile attack from either face of the prochiral oxocarbenium ion (Scheme 3B). ${ }^{4,7}$ Reversible collapse of the ion pair would lead to racemization of the substrate on the reaction time scale. ${ }^{8}$ We endeavored to design a set of experiments that would distinguish between each of these mechanistic possibilities.

We first sought to determine whether thiourea catalyst 1a induces racemization of $\mathbf{2}$ under conditions relevant to catalysis. Enantioenriched a-chloroisochroman, 2, could not be accessed, so it was not possible to track racemization by monitoring loss of optical activity. However, NMR spectroscopic techniques did afford methods for monitoring chemical exchange of the diastereotopic protons of racemic ( \pm )-2 over a range of timescales. ${ }^{9}$ The ${ }^{1} \mathrm{H}$ NMR signals for diastereotopic protons $\mathrm{H}^{\mathrm{a}} / \mathrm{H}^{\mathrm{b}}$ or $\mathrm{H}^{\mathrm{c}} / \mathrm{H}^{\mathrm{d}}$ (Figure $1 \mathrm{~A}$ ) do not coalesce in the 
absence or presence of catalyst 1a, even at temperatures as high as $70{ }^{\circ} \mathrm{C}$ in toluene- $d_{8}$, indicating that racemization must be slower than the differences in the Larmour frequencies of these protons (i.e. $k_{\mathrm{rac}}<\sim 10^{2} \mathrm{~s}^{-1}$ ) at these temperatures.

In order to monitor chemical exchange on the slower spin-lattice relaxation $\left(T_{1}\right)$ timescale, we applied a selective inversion-recovery (SIR) experiment. ${ }^{10,11}$ Competitive magnetization transfer by nuclear Overhauser effect (nOe) pathways could be minimized by studying the epimerization of a-chloroisochroman- $d_{3}$ (as a mixture of diastereomers $\mathbf{5 a}$ and $\mathbf{5 b}$, Figure $1 \mathrm{~A})$ as a proxy for racemization. With these considerations, chemical exchange could be readily detected in the presence of catalyst. ${ }^{12}$ The SIR data obtained over a range of total catalyst concentrations, $[\mathbf{1}]_{\mathrm{T}}$, were fit in order to extract values for the $1^{\text {st }}$-order rate constants, $k_{\mathrm{obs}}$, and the spin-lattice relaxation constant, $T_{1} \cdot{ }^{13}$ In this manner, it was possible to establish that the rate of epimerization is correlated directly with $[\mathbf{1}]_{\mathrm{T}}$ with both thiourea 1a and its urea analog, 1b (Figure 1B, C). No epimerization occurs in the absence of catalyst. This result effectively rules out a stereospecific mechanism for catalytic alkylation that relies on catalyst-independent substrate racemization (Scheme 3A-i).

On the basis of the epimerization rate data alone, the $\mathrm{S}_{\mathrm{N}} 1$ mechanistic manifold (Scheme 3B) cannot be distinguished from an $\mathrm{S}_{\mathrm{N}} 2$ mechanism involving catalyst-mediated $\mathrm{a}$ chloroisochroman racemization (Scheme 3C). However, racemization of 2 through an $\mathrm{S}_{\mathrm{N}} 1$ mechanism should be inhibited by exogenous chloride sources. ${ }^{4}$ In contrast, racemization through an $\mathrm{S}_{\mathrm{N}} 2$ mechanism should be promoted by an increased concentration of an exogenous chloride nucleophile. Accordingly, the SIR experiments were repeated with the addition of tetraoctylammonium chloride or hydrogen chloride (such that $\left[\mathrm{Cl}^{-}\right]=[\mathbf{1}]_{\mathrm{T}}$ ). In both cases, the exogenous chloride sources suppressed epimerization completely within the limits of detection.

Taken together, the data are most consistent with an $\mathrm{S}_{\mathrm{N}} 1$ mechanism for substrate racemization, wherein catalystpromoted substrate ionization leads to formation of an oxocarbenium•chloride ion pair. Substrate epimerization and alkylation share the same kinetic dependence on catalyst and a-chloroether, indicating that the two processes share a common transition-state stoichiometry. Direct comparison of the rate laws reveals that epimerization catalyzed by $\mathbf{1 a}$ or $\mathbf{1 b}$ is $10^{1}-10^{3}$ times faster than alkylation $\left(k_{\mathrm{rel}}=k_{\mathrm{epi}} /\right.$ $\left(k_{\text {cat }}{ }^{\bullet}[3]\right) \sim 4-13$ for 1a; $k_{\text {rel }}=k_{\text {epi }} /\left(k_{\text {cat }} \cdot[3]\right) \sim 150-440$ for $\left.1 \mathbf{b}\right),{ }^{14}$ as would be necessary for alkylation via either the dynamic kinetic resolution manifold in Scheme $3 \mathrm{C}$ or the stereoablative $\mathrm{S}_{\mathrm{N}} 1$ mechanism in Scheme 3B. While the two possibilities are indistinguishable based on the kinetic data, the fact that the highly electrophilic oxocarbenium•chloride ion pair is generated in the epimerization implicates it as an intermediate in the alkylation as well. Accordingly, we propose that the alkylation reaction proceeds via the anion-abstraction ion-pairing mechanism depicted in Scheme 3B.

Analysis of the a-chloroether epimerization kinetics also sheds light on the mechanism by which dual H-bond donors effect anion abstraction. Catalysts $\mathbf{1 a}$ and $\mathbf{1 b}$ have been shown to exist predominantly in dimeric states under the conditions examined in this study. ${ }^{3}$ The apparent $1_{\mathrm{st}^{-}}$order dependence of epimerization on $[\mathbf{1 a}]_{\mathrm{T}}$ (Figure 1B) is therefore indicative of the transition structure for anion abstraction engaging two molecules of catalyst. The 
deviation from $1_{\text {st }}$-order dependence on $[\mathbf{1 b}]^{\mathrm{T}}$ is analogous to the kinetic behavior observed for alkylation with both $\mathbf{1 a}$ and $\mathbf{1 b},{ }^{3}$ wherein a shift to a deaggregated monomeric resting state results in a $2_{\text {nd }}$-order dependence on catalyst at low $[\mathbf{1 b}]_{\mathrm{T}}{ }^{15}$

Two different mechanisms for cooperative anion abstraction consistent with this kinetic analysis are depicted in Figure 2. Anion abstraction via "4H"-binding would involve simultaneous association of both dual H-bond donor motifs directly to chloride during the abstraction event. This type of $4 \mathrm{H}$-anion binding is observed between thiourea 1a and chloride in the solid state. ${ }^{3}$ Cooperative anion abstraction via " $2 \mathrm{H}$ "-binding could proceed via association of one $\mathrm{H}$-bond donor to another, resulting in a stronger dual H-bond interaction with the anion. A $2 \mathrm{H}$-activation mode has been invoked by Smith and others to describe reactions enabled by designed, linked $\mathrm{H}$-bonddonor catalysts for activation of carbonyl compounds. ${ }^{16}$ Both mechanisms in Figure 2 proceed through the same transition state stoichiometry and are, therefore, kinetically indistinguishable. We probed the $4 \mathrm{H}$-and $2 \mathrm{H}$-ground state $(\mathbf{1})_{2} \cdot \mathrm{Cl}^{-}$complexes computationally using density functional theory (DFT), and found that they are remarkably similar in energy across different functionals, basis sets, and solvation models. ${ }^{17}$ As such, it is likely that both activation modes are energetically accessible; the dominant pathway may depend on the specific reaction parameters. The development of dimeric catalysts specifically linked in ways that enforce either of the two proposed activation modes may shed light on the operative mechanism and is expected to lead to more active catalysts with enhanced anion-abstraction capabilities.

\section{Supplementary Material}

Refer to Web version on PubMed Central for supplementary material.

\section{ACKNOWLEDGMENT}

This work was supported by the NIH (GM-43214) and by fellowships to D.L. (NSERC PDF), D.D.F. (Eli Lilly and Co.) and C.R.K. (NSF DGE1144152). The authors thank Dr. Sarah E. Reisman (Caltech) and Dr. Stephan J. Zuend (BASF) for contributions to the early stages of this project and for numerous helpful discussions, and Dr. Eugene E. Kwan for helpful discussions.

\section{ABBREVIATIONS}

$\begin{array}{ll}\mathrm{Ar}^{F} & \text { 3,5-bis(trifluoromethyl)phenyl } \\ \text { DFT } & \text { density functional theory } \\ \text { E } & \text { generic electrophile } \\ \text { nOe } & \text { nuclear Overhauser effect } \\ \text { SIR } & \text { selective inversion-recovery }\end{array}$

\section{REFERENCES}

(1) (a). For reviews, see: Zhang Z; Schreiner PR Chem. Soc. Rev 2009, 38, 1187-1198; [PubMed: 19421588] (b)Brak K; Jacobsen EN Angew. Chem. Int. Ed 2012, 52, 534-561;(c)Phipps RJ; Hamilton GL; Toste FD Nature Chem 2012, 4, 603-614; [PubMed: 22824891] (d)Beckendorf S, 
Asmus S; Mancheño OG Chem. Cat. Chem 2012, 4, 926-936;(e)Mahlau M; List B Angew. Chem. Int. Ed 2013, 52, 518-533;(f)Seidel D Synlett 2014, 25, 783-794.

(2) (a). For select examples of enantioselective anion-binding ca-talysis with dual H-bond donors, see: Taylor MS; Tokunaga N; Jacobsen EN Angew. Chem. Int. Ed 2005, 44, 6700-6704;(b)Raheem IT; Thiara PV; Peterson EA; Jacobsen EN J. Am. Chem. Soc 2007, 129, 13404-13405; [PubMed: 17941641] (c)Reisman SE; Doyle AG; Jacobsen EN J. Am. Chem. Soc 2008, 130, 7198-7199; [PubMed: 18479086] (d)Klausen RS; Jacobsen EN Org. Lett 2009, 11, 887-890; [PubMed: 19178157] (e)De CK; Klauber EG; Seidel D J. Am. Chem. Soc 2009, 131, 17060-17061; [PubMed: 19929016] (f)Xu H; Zuend SJ; Woll MG; Tao Y; Jacobsen EN Science, 2010, 327, 986-990; [PubMed: 20167783] (g)Knowles RR; Lin S; Jacobsen EN J. Am. Chem. Soc 2010, 132, 5030-5032; [PubMed: 20369901] (h)Brown AR; Kuo W-H; Jacobsen EN J. Am. Chem. Soc 2010, 132, 9286-9288; [PubMed: 20568761] (i)Burns NZ; Witten MG; Jacobsen EN J. Am. Chem. Soc 2011, 133, 14578-14581; [PubMed: 21848300] (j)Lin S; Jacobsen EN Nature Chem 2012, 4, 817-824; [PubMed: 23000995] (k)Schafer AG, Wieting JM, Fisher TJ; Mattson AE Angew. Chem. Int. Ed 2013, 52, 11321- 11324;(1)Metz AE; Ramalingam K; Kozlowski MC Tetrahe-dron Lett 2015, 5180-5184;(m)Mittal N; Lippert KM; De CK; Klauber EG; Emge TJ; Schreiner PR; Seidel DJ Am. Chem. Soc 2015, 137, 5748-5758.

(3) (a). Ford DD; Lehnherr D; Kennedy CR; Jacobsen ENJAm.Chem.Soc2016,Submitted http:// dx.doi.org/10.1021.jacs.0000000;(b)Ford DD “The Role of Catalyst-Catalyst Interactions in Asymmetric Catalysis with (salen)Co(III) Complexes and H-Bond Donors” Ph.D. Thesis, Harvard University, 2013.

(4) (a). Smith MB; March J In March's Advanced Organic Chemistry. Reactions, Mechanisms, and Structure, 6th ed.; Wiley: Hoboken, NJ, 2007; pp 425-512;(b)Anslyn EV; Dougherty DA In Modern Physical Organic Chemistry; University Science Books: USA, 2006; pp 637-668.

(5) (a). For theoretical treatment and select reviews, see: Noyori R; Tokunaga M; Kitamura M Bull. Chem. Soc. Jpn 1995, 68, 36-55;(b)Ward RS Tetrahedron Asymm 1995, 6, 1475-1490; (c)Caddick S; Jenkins K Chem. Soc. Rev 1996, 25, 447-456;(d)Huerta FF; Minidis ABE; Bäckvall J-E Chem. Soc. Rev 2001, 30, 321-331;(e)Pellissier H Tetrahedron, 2003, 59, 82918327;(f)Pellissier H Tetrahedron, 2008, 64, 1563-1601;(g)Pellissier H Tetrahedron, 2011, 67, 3769-3802.

(6). In principle, greater than $50 \%$ yield could be achieved without racemization via two parallel stereospecific mechanisms, one invertive and one retentive, to transform each of the enantiomers of 2 into a single enantiomer of product. While highly unusual, this mech-anistic manifold has precedent in the context of SN2' allylic substitu-tion reactions: Ito H; Kunii S; Sawamura M Nature Chem 2010, 2, 972-976. [PubMed: 20966955]

(7). For discussion of catalytic, enantioselective, stereoablative reactions, see: Mohr JT; Ebner DC; Stoltz BM Org. Biomol. Chem 2007, 5, 3571-3576. [PubMed: 17971984]

(8). The reaction displays a 1st-order dependence on nucleo-phile (ref 3), ruling out a mechanism proceeding through rate-limiting ionization.

(9) (a). McConnell HM J. Chem. Phys 1958, 28, 430-431;(b)Forsén S; Hoffman RA J. Chem. Phys 1963, 39, 2892-2901;(c)Bain AD Prog. Nucl. Mag. Res. Sp 2003, 43, 63-103.

(10) (a). Bain AD; Cramer JA J. Phys. Chem 1993, 97, 2884-2887;(b)Williams JT; Kershaw AD; Li V; Wu XJ Chem. Ed 2011, 88, 665-669.

(11) (a). For select recent examples using SIR to measure equilibri-um first-order rate constants ranging from 10-2 to 101 s-1, see: Bradley CA; Lobkovsky E; Keresztes I; Chirik PJ J. Am. Chem. Soc 2005, 127, 10291-10304; [PubMed: 16028941] (b)Davis AV; Fiedler D; Seeber G; Zahl A; van Eldik R; Raymond KN J. Am. Chem. Soc 2006, 128, 1324-1333; [PubMed: 16433551] (c)Goodman J; Grushin VV; Larichev RB; Macgregor SA; Marshall WJ; Roe DC J. Am. Chem. Soc 2009, 131, 4236-4238; [PubMed: 19317501] (d)Conley BL; Williams TJ J. Am. Chem. Soc 2010, 132, 1764-1765; [PubMed: 20088526] (e)Gonsales SA; Pas-cualini ME; Ghiviriga, Veige AS Chem. Commun 2015, 51, 13404-13407.

(12). These experiments were conducted at $-40^{\circ} \mathrm{C}$ in toluene-d 8 to enable accurate rate measurements. Qualitatively similar behavior is observed at temperatures ranging from $-50{ }^{\circ} \mathrm{C}$ to $-20{ }^{\circ} \mathrm{C}$, and activation parameters $(\mathrm{H} \ddagger=10.8 \pm 0.8 \mathrm{kcal} \mathrm{mol}-1, \mathrm{~S} \ddagger=-16 \pm 3 \mathrm{cal} \mathrm{mol}-1 \mathrm{~K}-1$ with catalyst 
1a) were calculated from the dependence of epimerization rate on temperature. See Supporting Information for details.

(13) (a). Bain AD; Cramer JA J. Magn. Reson 1996, 118 A, 21-27;(b)CFIT Program, Version 2.0, Bain AD, McMaster University, Hamilton ON, 2000 (http://www.chemistry.mcmaster.ca/bain/).

(14). See Supporting Information for details regarding the calcu-lations and approximations used to make this comparison.

(15). Both in this study and in the previously reported examina-tion of the alkylation kinetics (ref 3), urea catalyst $1 \mathrm{~b}$ is found to exhibit kinetic behavior consistent with weaker self-dimerization than thiourea catalyst 1a. The use of a more nonpolar solvent (toluene-d8 vs. tert-butyl methyl ether) for this study accounts for the greater absolute degree of dimerization observed here for both catalysts.

(16) (a). Jones CR; Pantoş GD; Morrison AJ; Smith MD Angew. Chem. Int. Ed 2009, 48, 7391-7394; (b)Probst N; Mada-rász Á; Valkonen A; Pápai I; Rissanen K; Neuvonen A; Pihko PM Angew. Chem. Int. Ed 2012, 51, 8495-8499;(c)Auvil TJ; Schafer AG; Mattson AE Eur. J. Org. Chem 2014, 2633-2646;(d)Spink SS; Kazakov OI; Kiesewetter ET; Kiesewetter MK Macromolecules, 2015, 48, 6127-6131; [PubMed: 27182086] (e)

(17). See Supporting Information for a summary of the methods 
A.<smiles>[CH][C@H]1OC(Cl)c2ccccc2[C@@H]1[18OH]</smiles><smiles>[2H]C1([2H])OC(Cl)c2ccccc2C1([2H])[2H]</smiles>

$( \pm)-2$

$( \pm)-5 a$

B.

$$
\begin{aligned}
& \text { rate }=\frac{4 k_{\mathrm{epi}}[1]_{\mathrm{T}}^{2}[2]}{\left(1+\sqrt{\left.1+8 K_{\operatorname{dim}[1]}\right]_{\mathrm{T}}}\right)^{2}} \\
& k_{\mathrm{obs}}=\frac{4 k_{\mathrm{epi}}[1]_{\mathrm{T}}^{2}}{\left(1+\sqrt{1+8 K_{\mathrm{dim}}[1]_{\mathrm{T}}}\right)^{2}} \\
& \text { when } 8 K_{\operatorname{dim}}[1]_{T} \gg 1 \\
& \text { (resting state dimer) } \\
& k_{\mathrm{obs}} \approx \frac{k_{\mathrm{epi}}}{2 K_{\mathrm{dim}}}[1]_{\mathrm{T}}
\end{aligned}
$$
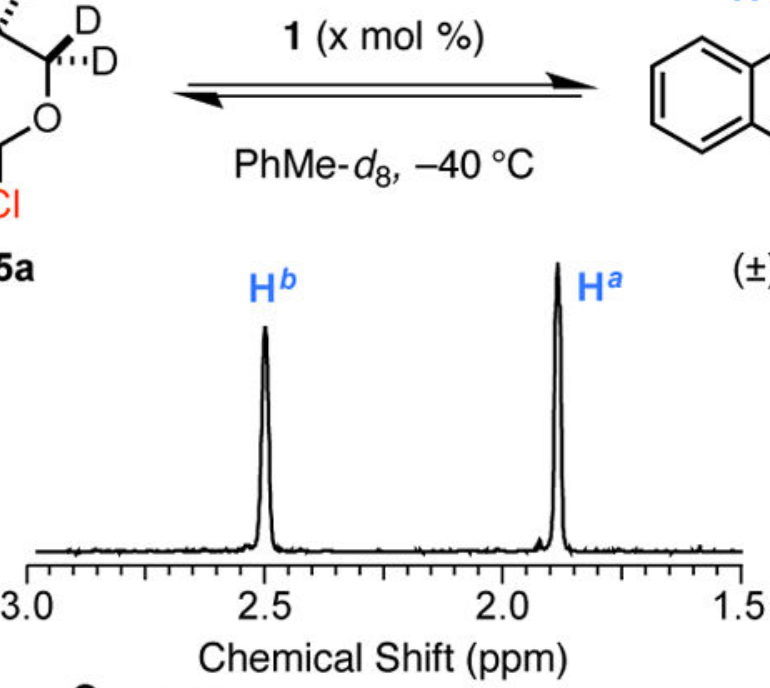

C. 2.0<smiles>[2H]C1([2H])O[C@H](Cl)c2ccccc2C1([2H])[2H]</smiles>

$( \pm)-5 b$

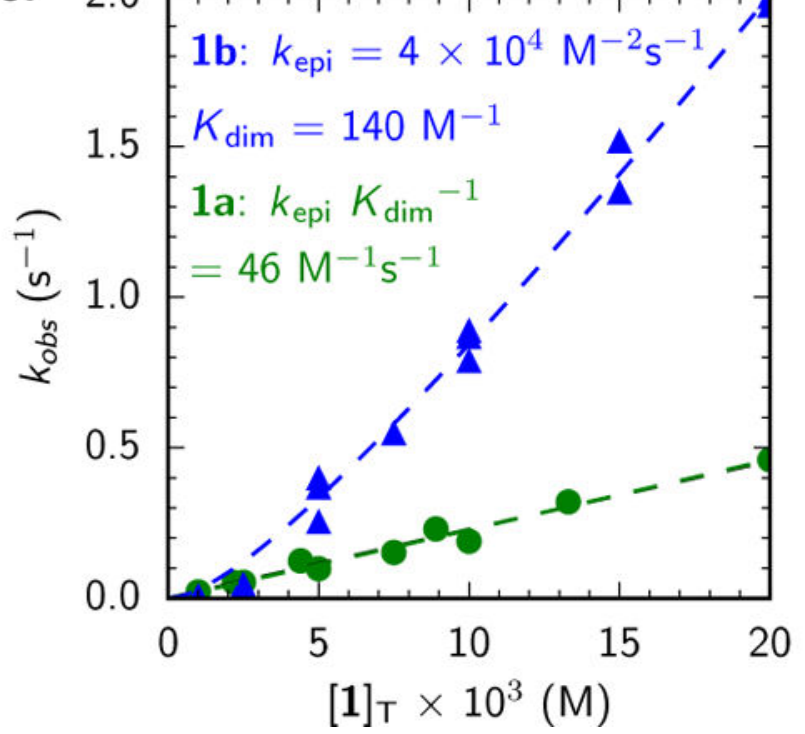

Figure 1.

A. Portion of the ${ }^{1} \mathrm{H}$ NMR spectrum of $( \pm)-5\left(\mathrm{C}_{6} \mathrm{D}_{6}, 23{ }^{\circ} \mathrm{C}\right)$. Inversion at $\mathrm{C} 1$ leads to chemical exchange between $\mathrm{H}^{a}$ and $\mathrm{H}^{b}$. B and C. Dependence of the observed first-order rate constant $k_{\mathrm{obs}}$ for epimerization of $\mathbf{5}$ on the total concentration of catalyst, fit to the rate law for epimerization. The rate constant was measured using selective inversion-recovery NMR experiments with [5] $=0.1 \mathrm{M}$ in toluene- $d_{8}$ at $-40{ }^{\circ} \mathrm{C}$. 
A. 4H-Anion-Abstraction

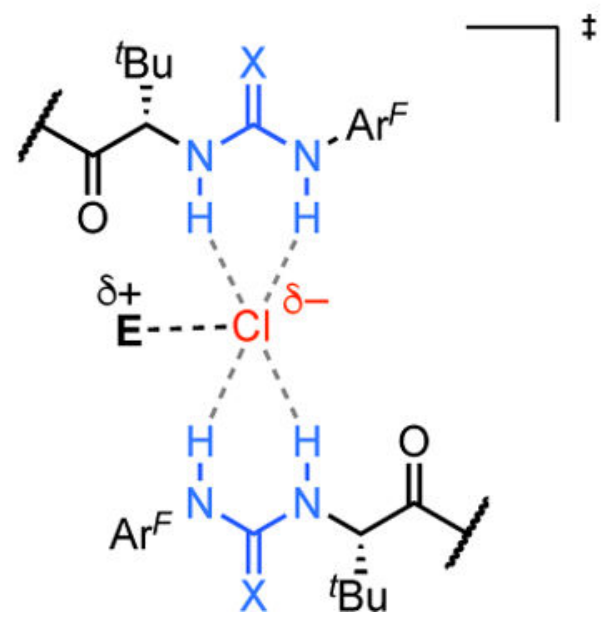

B. 2H-Anion-Abstraction

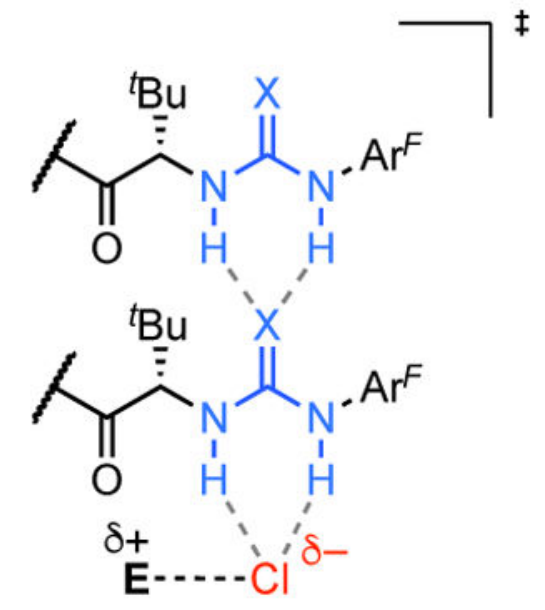

Figure 2.

Two potential cooperative modes of chloride abstraction. $\mathrm{E}=$ generic electrophile 
A. Binding Pre-Formed Ion Pairs ${ }^{b}$

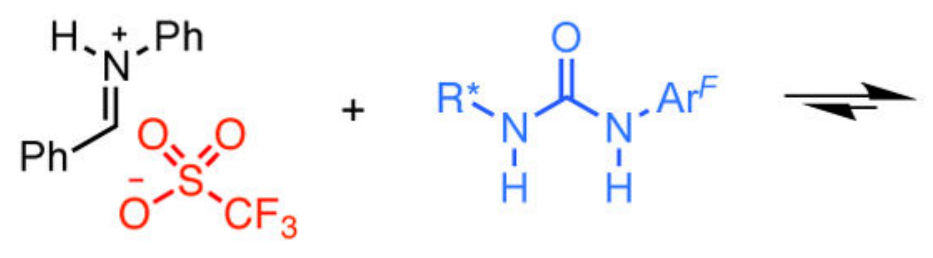

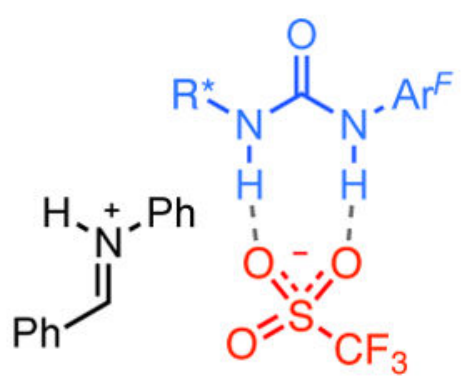

B. Brønsted Acid Co-Catalysis ${ }^{c}$<smiles>C(=N/CCc1c[nH]c2ccccc12)\c1ccccc1</smiles><smiles>[R7]NC(=S)N([AlH2])[AlH]OC(=O)O</smiles><smiles>[R7]N([IH])C(=S)N([Al-])[Al][IH]OC(=O)Cc1c[nH]c2ccccc12</smiles>

C. Anion-Abstraction Catalysis ${ }^{d}$<smiles>ClC1OCCc2ccccc21</smiles>

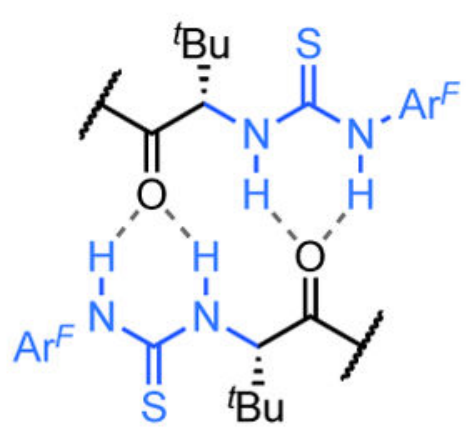<smiles>[2H][C@@H]1C=C[C@@H]1C</smiles><smiles>CCN(C)C(=S)N(CC)CC</smiles>

${ }^{a} \mathrm{Ar}^{F}=3,5$-bis(trifluoromethylphenyl). ${ }^{b}$ See ref $2 \mathrm{f} .{ }^{c}$ See ref $2 \mathrm{~d} .{ }^{d}$ See ref $2 c, 3$. 
Ford et al.<smiles>ClC1OCCc2ccccc21</smiles>

$( \pm)-2$<smiles>COC(OC)=C(C)C</smiles>

3

catalysts:

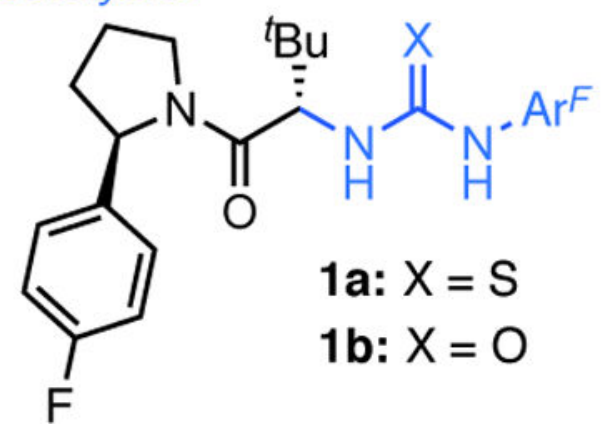

Page 10

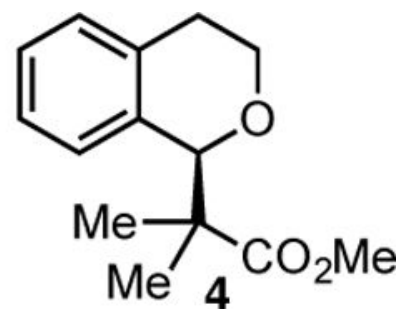

$92 \%$ yield 92\% ee with catalyst 1a

Scheme 2.

Model system for mechanistic analysis. 
A. $S_{N} 2$-type
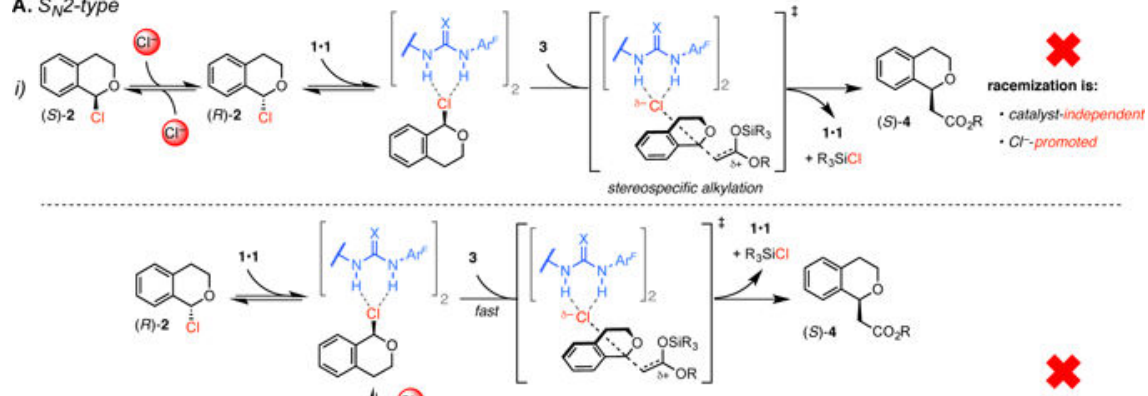

ii)

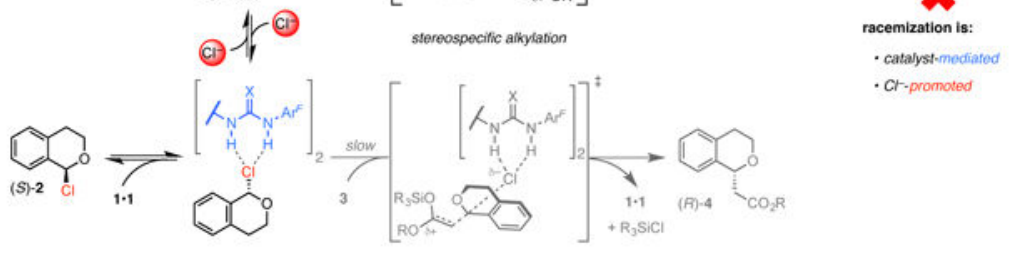

B. $S_{N}{ }^{1-t y p e}$

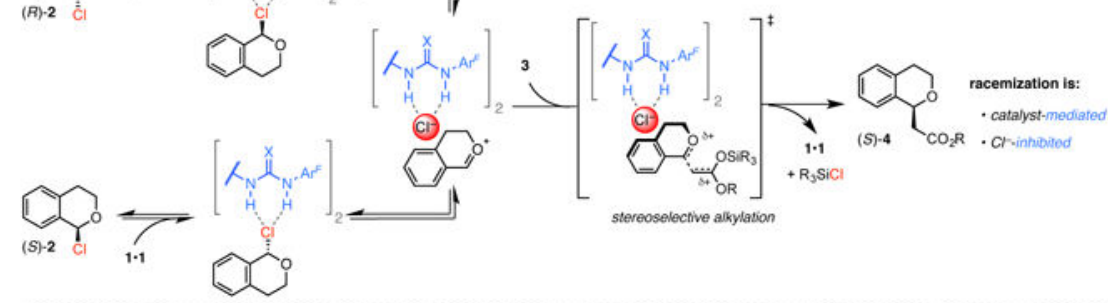

C. Mixed $S_{N} 1 / S_{N} 2$-type

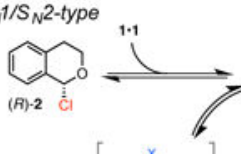

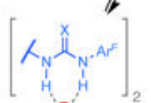
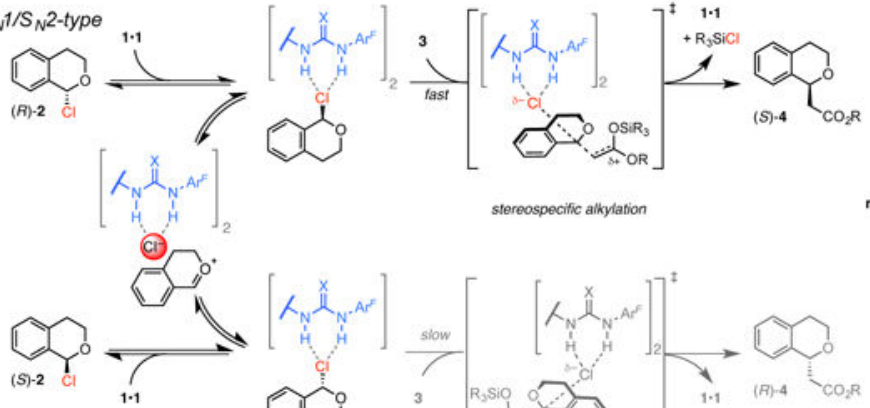

stereospecific alkyiation

Acemization is:

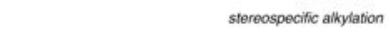

- catalyst-mediated

- $\mathrm{Cl}$-sinhibited

Scheme 3. Possible Mechanisms for a-Chloroisochroman Activation.

ACS Catal. Author manuscript; available in PMC 2019 November 21. 